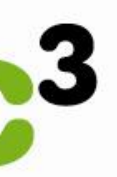

BASQUE CENTRE

FOR CLIMATE CHANGE

Klima Aldaketa Ikergai

Modeling the Links between Biodiversity, Ecosystem Services and Human Wellbeing in the Context of Climate Change: Results from an Econometric Analysis on the European Forest Ecosystems

Helen Ding and Paulo A.L.D. Nunes

October 2012

BC3 WORKING PAPER SERIES 
The Basque Centre for Climate Change (BC3) is a Research Centre based in the Basque Country, which aims at contributing to long-term research on the causes and consequences of Climate Change in order to foster the creation of knowledge in this multidisciplinary science.

The BC3 promotes a highly-qualified team of researchers with the primary objective of achieving excellence in research, training and dissemination. The Scientific Plan of BC3 is led by the Scientific Director, Prof. Anil Markandya.

The core research avenues are:

- $\quad$ Adaptation to and the impacts of climate change

- $\quad$ Measures to mitigate the amount of climate change experienced

- International Dimensions of Climate Policy

- Developing and supporting research that informs climate policy in the Basque Country

See www.bc3research.org for further details.

The BC3 Working Paper Series is available on the internet at http://www.bc3research.org/working papers/view.html

Enquiries (Regarding the BC3 Working Paper Series):

Roger Fouquet

Email: roger.fouquet@bc3research.org

The opinions expressed in this working paper do not necessarily reflect the position of Basque Centre for Climate Change (BC3) as a whole.

Note: If printed, please remember to print on both sides. Also, perhaps try two pages on one side. 


\title{
Modeling the links between biodiversity, ecosystem services and human wellbeing in the context of climate change: results from an econometric analysis on the European forest ecosystems
}

\author{
Helen Ding ${ }^{(1)}$ and Paulo A.L.D. Nunes ${ }^{(2)}$
}

(1) Biodiversity Governance Research Unit (BIOGOV), Center for Philosophy of Law (CPDR),

Université catholique de Louvain, Belgum; (2) The Mediterranean Science Commission, Monaco

\begin{abstract}
The paper conducts an empirical investigation on the complex relationship between biodiversity and the values of ecosystem goods and services that are supported by biodiversity and ecosystem functioning, aiming to produce an econometric quantification of the magnitudes involved. Furthermore, we operate this study at a in the context of global climate change, which is considered one of the major drivers today that alter the pattern of biodiversity distribution, affect the ecosystem functioning and change the flows of ecosystem goods and services to be provided by a healthy ecosystem. In the paper, we first built a composite biodiversity indicator on the concept of Natural Capital Index so as to integrate information regarding the quantitative and qualitative changes of ecosystems driven by warming climate conditions. Furthermore, the composite indicator is integrated into the econometric specification so as to capture the marginal impacts of changes in biodiversity on the value of ecosystem goods and services due to climate change. The econometric problem is solved in a structural simultaneous system using three-stage-least-squares (3SLS) to analyze climate change impacts on forest ecosystems and the respective ecosystem service values across 17 European countries.
\end{abstract}

Keywords: 3SLS, composite biodiversity indicator, European forest ecosystem services, climate

change impact

JEL Classification: Q23, Q51, Q57

Cite as: Ding, H. and P.A.L.D. Nunes (2012) Modeling the links between biodiversity, ecosystem services and human wellbeing in the context of climate change: results from an econometric analysis on the European forest ecosystems. BC3 Working Paper Series 2012-12. Basque Centre for Climate Change (BC3). Bilbao, Spain. 


\section{Introduction}

Current model projections have consistently indicated that biodiversity would continue to decline over the 21 st century, under different socioeconomic scenarios with trajectories of key indirect drivers of ecological changes, such as human population growth and greenhouse gas emissions (GHG) (Pereira et al., 2010; Leadley, et al. 2010). This in turn will impose threats to the benefits of future humanity and result in a change in our production and consumption patterns in the long run (Martens et al., 2003), as biodiversity underpins a variety of ecosystem services that are vital to human well-being.

Biodiversity by definition encompasses the variety of life on earth from genes to species, through to the broad scale of ecosystems across time and space. It is important in terms of determining the health of ecosystem, ensuring the stability and productivity of ecosystem, as well as contributing directly or indirectly to human wellbeing. In this regard, the term "biodiversity" is used largely as an assumed foundation for ecosystem processes, rather than simply the changing number of species on a species list. The relationship between biodiversity and ecosystem functioning or primary productivity has been of long-standing interest to ecologists (Kinzig et al., 2001; Loreau et al., 2001, 2002; Cameron, 2002). Over the past years, the subject has been researched in various ways: via experimental filed research, the formulation of mechanistic theories, and quantitative field observation, most of which have led to a common conclusion that a large variety of species has a positive influence on the productivity and stability of ecosystems, as greater biodiversity can cope with various circumstances in a given habitat and thus lead to the more efficient use of available natural resources (Martens et al, 2003; Loreau et al, 2001). Nonetheless, quantifying the link between biodiversity and ecosystem services remains a major scientific challenge to date (Pereira et al., 2010), because there does not exist a general ecological relationship between ecosystem function and diversity owing to species-specific effects and important tropic links (Paine, 2002; Willims et al., 2002). Certainly, biodiversity loss will negatively affect ecosystem functioning by changing the composition and distribution of species (Giller and O'Donovan, 2002; Schmid et al., 2000; Bloger, 2001; Loreau et al., 2001), which may have far-reaching socioeconomic consequences in the future, through the provision of ecosystem services to human society (Martens et al, 2003). Thus how to explicitly quantify the effect of biodiversity loss on human welfare has become a great challenge to the economists today.

In fact, the economics literature has shown many attempts to both conceptualize and value biodiversity, exploring the use of stated- and revealed- preference valuation methods, both of which intend to estimate the marginal impact of biodiversity loss on utility (Kontoleon et al., 2007). These methods have been largely used to estimate the nonmarket values of biodiversity. On the other hand, biodiversity also have considerable market value through the supply of important inputs for economic production. Thus, the total value of biodiversity or ecosystems should encompass an array of ecosystems goods and services (EGS), including provisioning, cultural, regulating and supporting services, upon which human livelihoods depend (MEA, 2005; Chiabai et al, forthcoming; Ding et al, 2010). However, numerical analysis of the links between biodiversity and human well-being remains crude in the literature due to the complex non-linear relationship between biodiversity and ecosystem functioning and services. In this regards, only two studies have attracted our particular attention, both of which exploring the use of different biodiversity indicators, i.e. species richness and threatened flora and fauna indexes in modeling the effect of biodiversity loss in the value of ecosystem services or ecosystem productivity. The first refers to a recent study conducted by Costanza et al. (2007), who numerically demonstrated a positive relationship between species richness and net primary production (NPP) for the US., followed by Ojea et al. (2009), who employed the use of meta-analysis that has greatly extended their investigation from regional forest ecosystem valuation studies to a global scale. 
Nonetheless, our knowledge about the role of biodiversity in ecosystem functioning is very limited, using an individual biodiversity indicator might be able to explain partly (not sufficiently enough) the impacts of biodiversity loss on the value of ecosystem services and thus human welfare, but meanwhile it may also lose a lot of other important information as most of the biodiversity indicators deal with only one biodiversity attribute or a specific policy target. Therefore, the creditability of the estimates from the previous studies for aiding policymaking might be questionable.

For this reason, the present paper aims at contributing to bringing this gap by constructing a composite biodiversity indicator which integrates information about species changes (e.g. change in the abundance or distribution of populations), and ecosystem changes (e.g. change in extent of particular biomes) in a climate change context. Furthermore, we will run an econometric model to test whether the constructed composite biodiversity indicator is sensitive to a set of factors causing global changes, including the growth of population and economy, the land-use changes, and the rising earth's temperature. In particular, we are interested in testing whether global warming will have a substantial impact on the changes in biodiversity and ecosystem services, which will consequently influence the ecosystem benefits that human can receive in the future (interpreted as welfare changes to human beings), holding all other conditions constant. Data availability with regards to both biological species and economic values of the ecosystem services led our analysis focus on the forest ecosystems in Europe.

The organization of the article is as follows. Section 2 discusses the key assumptions of four different climate change scenarios and the respective impacts on the future patterns of biodiversity in Europe. Data regarding projections of socio-economic, ecologic and climatic conditions under future scenarios are also presented. Section 3 focuses on constructing a new composite biodiversity indicator for the study of climate change impact. Section 4 employs the use of three stages least squares (3SLS) model for testing the new composite biodiversity indicator and shows some preliminary results. Section 5 concludes.

\section{The Future Pattern of Biodiversity in the Context of Climate Change}

\subsection{Climate scenarios for projecting the future trends of biodiversity}

Scenarios do not predict the future, but rather paint pictures of possible futures and explore the various outcomes that might result if certain basic assumptions are changed. In order to explore the possible future biodiversity patterns in Europe, the scenarios used are based on the recent efforts of the IPCC (IPCC, 2000), which explore the global and regional dynamics that may result from changes at a political, economic, demographic, technological and social level. The distinction between classes of scenarios was broadly structured by defining them ex ante along two dimensions. The first dimension relates to the extent both of economic convergence and of social and cultural interactions across regions; the second has to do with the balance between economic objectives and environmental and equality objectives. This process therefore led to the creation of four scenarios families, namely A1, A2, B1 and B2 storylines, each of which contains a number of specific scenarios (IPCC, 2000). Hereafter, we call them IPCC scenarios throughout the paper. Table 1 below summarizes the political, economic, demographic, technological and social assumptions made in each of the IPCC scenarios and analyzes their potential impacts on the future patterns of global biodiversity.

Table 1 IPCC scenarios of future global biodiversity patterns

\begin{tabular}{|c|c|c|c|}
\hline Storyline & Key assumptions & $\begin{array}{l}\text { Summary of major effects of } \\
\text { the scenario }\end{array}$ & Impacts on biodiversity \\
\hline A1 & Slight population increase till & Many pristine natural areas are & Patterns of bird and \\
\hline
\end{tabular}




\begin{tabular}{|c|c|c|c|}
\hline $\begin{array}{l}\text { (offers an } \\
\text { unfavorable } \\
\text { perspective } \\
\text { for } \\
\text { biodiversity) }\end{array}$ & $\begin{array}{l}2050, \text { then decrease; Very } \\
\text { rapid economic growth; High } \\
\text { level of income; A global } \\
\text { mean increase in temperature } \\
\text { of at least } 4.4^{\circ} \mathrm{C} \text { (std } 0.9 \text { ) } \\
\text { toward } 2080 ; \text { Forest area is } \\
\text { stable due to increasing timber } \\
\text { demand and recreational land } \\
\text { use pressure. Significant } \\
\text { conversion of agricultural land } \\
\text { from food to bioenergy } \\
\text { production. }\end{array}$ & $\begin{array}{l}\text { converted into man-made } \\
\text { areas; Costs of preserving } \\
\text { natural areas are very high due } \\
\text { to increase in land prices; } \\
\text { Reduced ecosystem quality } \\
\text { due to increased population } \\
\text { densities, increased tourism, } \\
\text { etc; Higher concentrations of } \\
\text { GHG due to a substantial } \\
\text { increase in energy use and } \\
\text { land conversion }\end{array}$ & $\begin{array}{l}\text { herptile species richness } \\
\text { will not change } \\
\text { dramatically; } \\
\text { Plant and tree species } \\
\text { richness will decrease in } \\
\text { the southern part of } \\
\text { Europe but increase in } \\
\text { central and Scandinavian } \\
\text { Europe. }\end{array}$ \\
\hline $\begin{array}{l}\text { A2 } \\
\text { (offers a } \\
\text { heterogeneous } \\
\text { world) }\end{array}$ & $\begin{array}{l}\text { Continually growing human } \\
\text { population (15 billion by } \\
2100) \text {; Slow economic growth; } \\
\text { Economic development is } \\
\text { primarily oriented and uneven; } \\
\text { Regional self-reliance in terms } \\
\text { of resources; Weak global } \\
\text { environmental concern; Total } \\
\text { consumption of natural } \\
\text { resources is considerable; A } \\
\text { global mean increase in } \\
\text { temperature of at least } 3.5^{\circ} \mathrm{C} \\
\text { (std 0.7) toward } 2080 ; \text { Slightly } \\
\text { decrease of forest area; } \\
\text { Significant conversion of } \\
\text { agricultural land from food to } \\
\text { bioenergy production and } \\
\text { human settlement. }\end{array}$ & $\begin{array}{l}\text { Sharply increasing demand for } \\
\text { foods, water, energy and land } \\
\text { will result in a significant loss } \\
\text { of natural ecosystems and } \\
\text { species; Regional competition } \\
\text { for good-quality natural } \\
\text { resources will negatively } \\
\text { affect the economic conditions } \\
\text { in these countries and reduce } \\
\text { attention for the preservation } \\
\text { of natural resources; An } \\
\text { increasing number of people } \\
\text { will compete for a declining } \\
\text { number of natural resources at } \\
\text { the cost of quantity and } \\
\text { quality of those remaining } \\
\text { resources. }\end{array}$ & $\begin{array}{l}\text { Patterns of bird and } \\
\text { herptile species richness } \\
\text { will not change } \\
\text { dramatically; } \\
\text { Plant and tree species } \\
\text { richness will decrease in } \\
\text { the southern part of } \\
\text { Europe but increase in } \\
\text { central and Scandinavian } \\
\text { Europe. }\end{array}$ \\
\hline $\begin{array}{l}\text { B1 } \\
\text { (offers a more } \\
\text { favorable } \\
\text { perspective } \\
\text { for } \\
\text { biodiversity) }\end{array}$ & $\begin{array}{l}\text { A sharp reduction in arable } \\
\text { farming and cattle breeding } \\
\text { acreage due to a strong } \\
\text { increase in productivity; The } \\
\text { estimated temperature increase } \\
\text { is about } 2.7^{\circ} \mathrm{C} \text { (std } 0.6 \text { ) toward } \\
2080 \text {; Pressure from } \\
\text { population growth is } \\
\text { considerably lower; Forest } \\
\text { area increases. Significant } \\
\text { conversion of agricultural land } \\
\text { from food to bioenergy } \\
\text { production and human } \\
\text { settlement. }\end{array}$ & $\begin{array}{l}\text { A lot is done to improve } \\
\text { ecological capital and } \\
\text { therefore reduce threatening } \\
\text { factors and prospects for } \\
\text { biodiversity; Cropland } \\
\text { production is concentrated in } \\
\text { optimal locations; Grassland is } \\
\text { protected by policy. }\end{array}$ & $\begin{array}{l}\text { Natural ecosystems are } \\
\text { less affected both in } \\
\text { quantity and quality }\end{array}$ \\
\hline $\begin{array}{l}\text { B2 } \\
\text { (very locally } \\
\text { concentrated } \\
\text { social, } \\
\text { economic and } \\
\text { ecological } \\
\text { problems) }\end{array}$ & $\begin{array}{l}\text { The pressure on natural system } \\
\text { is greatly reduced due to high } \\
\text { average education levels and } \\
\text { high degree of organization } \\
\text { within communities; } \\
\text { Stable population; Relatively } \\
\text { slow economic development; } \\
\text { Regionally and locally } \\
\text { oriented anvironmental }\end{array}$ & $\begin{array}{l}\text { The general picture of } \\
\text { biodiversity in the future } \\
\text { largely depends on the } \\
\text { introduction of socio- } \\
\text { economic policies that support } \\
\text { local and regional initiatives to } \\
\text { achieve structural solutions. }\end{array}$ & $\begin{array}{l}\text { Hard to estimate global } \\
\text { biodiversity trend due to } \\
\text { the high heterogeneity }\end{array}$ \\
\hline
\end{tabular}


policies are successful; A

global mean increase in

temperature of at least $2.0^{\circ} \mathrm{C}$

(std 0.7) toward 2080; Land-

use changes from food to

bioenergy production or

forestry.

Source: adapted from Martens et al. (2003) and ATEAM model assumptions

On the contrary, the B-type scenarios depict a world, where economic objectives and environmental and equity objectives are more balanced. From a global sustainability perspective, Scenario B1 shows that environmental and social consciousness can be combined in a more sustainable development manner, offering a more favorable perspective for biodiversity than the Atype scenarios. Moreover, technological development is expected to shift towards renewable energy and higher productivity and consequently reduce the pressure on natural ecosystems from decreased pollution and land conversion. Finally, biodiversity will also benefit from lower pressure of global population growth and improved ecological capital. Similarly to scenario B1, the B2 scenario is environmentally oriented with a focus on both environmental and social sustainability, but locally oriented. In this scenario, average education level and degrees of organization within communities are high and energy and material efficiency can be achieved. All these social and technological achievements can reduce the pressure on natural ecosystem. However, it is difficult to predict a global trend of biodiversity due to the large regional difference, including socio-economic policies that support land and regional initiatives.

\subsection{Data: projections under the IPCC Storylines}

Under different IPCC storylines, projections have been developed to describe possible outcomes of different political, economic, demographic, technological and social assumptions for the future development. These include the projected trends of GDP, population, incremental temperature, ecosystem productivity, distribution of species and so on, subject to the changes in a set of key assumptions on which the IPCC storylines are based (see Table 1). In this study, we explore the use of climatic, socio-economic and ecological projections to investigate the pressure on biodiversity and to quantify the consequent quality and quantity changes of terrestrial biodiversity following four future development paths. As for the scale of the study, only 17 European countries are taken into account due to the limited data availability regarding number of biological species projected under climate change scenarios. In addition, empirical evidence has shown that the impacts of changing climate conditions are highly spatially heterogeneous, as organisms, populations and ecological communities do not respond to approximated average of global warming (Walther et al., 2002). To account for regional climate differences, we further divide the 17 European countries into 3 geo-climatic clusters, namely Mediterranean Europe (Greece, Italy, Portugal, Spain), Central North Europe (Austria, Belgium, France, Germany, Ireland, Luxembourg, Netherlands, Switzerland, United Kingdom), and Scandinavian Europe (Denmark, Finland, Norway, Sweden), where similar climatic patterns and taxa might be identified.

The data used are independently published by a number of IPCC data distribution centers across the world for 2050, downscaled at country level. The demographic and economic trends represented by the future per capita GDP, population density are projected and distributed by the Center for International Earth Science Information Network (CIESIN, 2002) at Columbia University. The annual mean temperature was projected by the Tyndall Centre in the UK (www.tyndall.ac.uk), which combined the use of Global Circulation Models/SRES (including CGCM2, CSIRO2, HadCM3 
and $\mathrm{PCM}$ ) to estimate the possible increase of temperature in degrees Celsius for each country under different IPCC scenarios. The biophysical changes of biodiversity comprises the quantitative change measured in terms of changes in the area of forest habitat, and the qualitative change indicated by changes in the number of terrestrial species (including plant, tree, bird and herptile). The future trends of these changes under IPCC scenarios are projected in the frame of the Advanced Terrestrial Ecosystem Analysis and Modelling (ATEAM) project (Schroeter, et al. 2004). In particular, species richness under current and future conditions are projected taking into account total 383 bird species, 108 reptile and amphibian species, 1350 plant species and 125 tree species appeared in the EU. To keep the consistency across a large range of data sources, we derive all data from projections that represent a combination with the HadCM3 model.

Our knowledge about to what extent biodiversity can respond to climate change is limited and the quantification of associated economic gains or losses to human welfare cannot be straightforward but through valuing biophysical changes of ecosystem services under future climate conditions. In this study, values of ecosystem goods and services provided by the European forests are taken from Ding et al. 2010, who provided detailed projections of ecosystem values following four future IPCC storylines vis-à-vis to the baseline year of 2000 . The valuation exercises were conducted separately for three types of ecosystem services defined in Millennium Ecosystem Assessment, i.e. provisioning, regulating and cultural services (MEA, 2005). More specifically, forest provisioning services contain the benefits derived from the production of timber and other wood forest products, regulating services provides non-monetary benefits from $\mathrm{CO} 2$ sequestration in the forest, and cultural services provides humans with direct incomes from the related tourism industries and non-monetary benefits from the enjoyment of existing forests. The market or non-market nature of different values of ecosystem services determined the use of various valuation methods and also indicated different degrees of biodiversity dependence. To capture the specific marginal effect of biodiversity on each ecosystem service, we keep the three types of values separately rather than using a summed total ecosystem value. All values were first projected to 2050 and then adjusted to 2005 US $\$$.

\section{The construction of simple composite biodiversity indicator}

The greatest challenge that scientists are facing today is to develop appropriate biodiversity metrics so as to measure and monitor the different dimensions of biodiversity and to predict the future trends of biodiversity and ecosystems. Moreover, these biodiversity measures should also be able to compass essential biological information, incorporate socioeconomic impacts, as well as guide policy interventions towards more effective biodiversity management. To this extent, the existing biodiversity data will be useful for developing quantitative scenarios of the future trajectories of biodiversity (Pereira et al., 2010). From a methodological perspective, there is a general need of creating a workable "calculus" of biodiversity that allows not just global summation, but also estimation of the more localized marginal gains and losses from global changes induced by socioeconomic development and land use changes in different places (Faith, 2005). These measures are therefore compatible with trade-offs and synergies in regional planning.

\subsection{Why composite indicator?}

Biodiversity indicators are developed for various purposes. By far, a long list of biodiversity measures has been developed to reflect a range of attributes and issues of concern. At global level, there are roughly 40 potential measures being developed for the Convention on Biological Diversity

\footnotetext{
${ }^{1}$ For valuation details and results, readers are recommended to refer to Ding et al (2010).
} 
(CBD) and about 26 indicators being considered in the Streaming Biodiversity Indicators in Europe 2010 process (Mace and Baillie, 2007). Nevertheless, for the purpose of public and business decisions and as an effective communication tool to broader audience, a single, simple or composite biodiversity measure might be more influential, just like the use of Gross Domestic Production (GDP) in economic analysis and the Dow Jones indicator in stock market (Mace and Baillie, 2007; Balmford, et al. 2005). There are now a number of composite indicators have been developed. For example, the Natural Capital Index (NCI) is constructed as a weighted sum of the product of the extent of each ecosystem (relative to a baseline) with the condition of the ecosystem, where the condition is measured as the population size of a group of indicator species relative to a baseline (ten Brink, 2000). A similar indicator is the Biodiversity Intactness Index (BII) recently developed by Scholes and Biggs (2005), which also takes into account different ecosystems being weighted by their species richness and population size being estimated for each land-use class in each ecosystem. Apparently, the latter requires more detailed information of species under each type of land-use. Given the limited data availability, we therefore propose to adopt the NCI approach to construct a similar composite indicator for analyzing climate change impacts on the biodiversity and ecosystem services in Europe.

$\mathrm{NCI}$ framework considers biodiversity as a natural resource containing all species with their abundance, distribution, and natural fluctuations. Human direct and indirect interference may affect ecosystem size (through land conversion) and exert pressures on ecosystem quality (such as overexploitation and fragmentations). As a result, both decreased ecosystem quantity and quality will lead to the loss of biodiversity. In this context, the development of NCI framework aims at providing a quantitative and meaningful picture of the state of and trends in biodiversity to support policymakers in a similar way as GDP, employment and Price Index do in economics. Moreover, the structure of $\mathrm{NCI}$ also allows the analysis of socio-economic scenarios on their effect on biodiversity. In technical terms, NCI is the product of changes in the size of ecosystems ("ecosystem quantity") and the changes in abundance of a core set of species ("ecosystem quality") within the remaining ecosystem, where both quality and quantity are expressed relative to an "optimal" or "intact" baseline (ten Brink, 2000).

\section{Equation of the NCI:}

$N C I=$ ecosystem quality (\% of species abundance $) \times$ ecosystem quantity $(\%$ area of the country)

Thus, the state of biodiversity and process of ecosystem degradation with respect to a baseline in a given policy context can be visualized using NCI - see Figure 1.
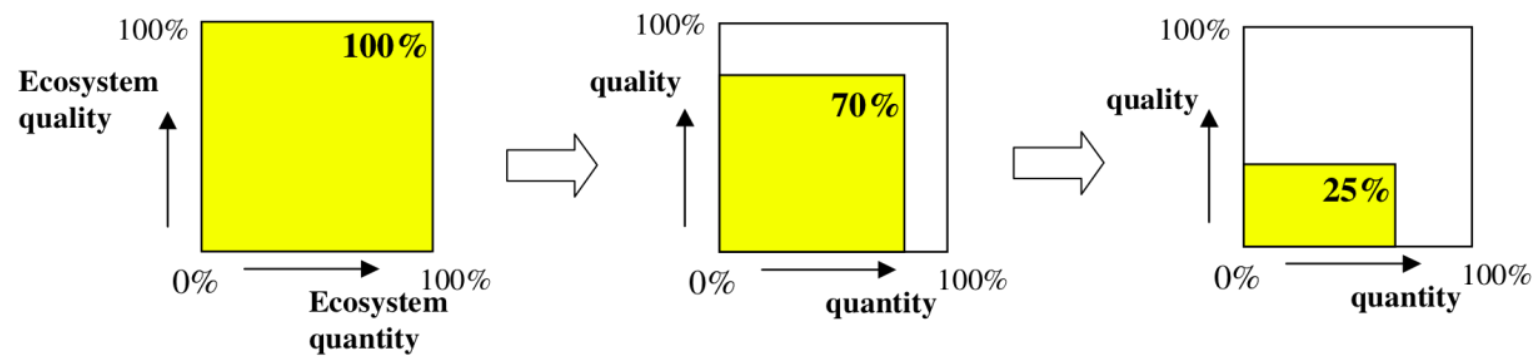

Figure 1. Trends of ecosystem quality and quantity using NCI (Source: Ten Brink (2007) pp.2)

The NCI chooses the use of less modified "pre-industrial baseline" so that major anthropogenic impacts on the changes of biodiversity quality (e.g. loss of species abundance) and quantity (e.g. loss of natural habitat) can be observed and compared. The NCI score ranges from 0 to 
$100 \%$ representing an entire deteriorated $(0 \%)$ and intact ecosystem (100\%), respectively. It summarizes the extent to which a landscape has preserved its original (baseline) natural capital and enables the analysis of biodiversity effects in different socio-economic scenarios. Obviously, one of the advantages of the NCI is that it allows us to aggregate many biodiversity parameters to a few or perhaps a single, more or less representative biodiversity index for the entire ecosystem (ten Brink, 2000).

3.2 Construct an aggregated NCI-like biodiversity composite indicators for the IPCC scenarios

To project the trends of biodiversity under future climate change pressure and their respective socio-economic impacts, it is impossible to use individual biodiversity indicators, such as species richness or abundance of a certain species, due to our limited knowledge about how individual species responds to an increase in temperature or precipitation rate and what are the consequences on ecosystem functioning and performance. Rather, a simple composite indicator similar to the NCI is ideal since it is designed in a way that biodiversity loss can be linked to socio-economic drivers as well as other anthropogenic impacts, including degradation of natural habitats, land-use changes and climate change. Moreover, it also aggregates information from a set of core species, such as tree, plant, bird, herptile, which determine together the overall ecosystem quality. Therefore, the future trends of ecosystem quality and quantity under different climate change scenarios can be assessed with respect to a selected baseline.

Subject to restrict data constraints, we set up our baseline year at 2000 and the policy target at 2050. This period is characterized as post-industrialization era, in which many stringent environmental policies have been successfully implemented among the most developed European economies, in terms of pollution reduction, sustainable resource management and promoting green economy. Thus, in our dataset, many countries are projected to have a stable increase in either forest area or increased richness of many species or both. Therefore, the original NCI score range ([0$100 \%]$ ) cannot apply, if we allow for an overall improvement of the forest ecosystems in some countries. Instead, we set up two intervals to indicate the state of the forest ecosystem under different future scenarios: (1) [0-100\%] indicates a degradation of ecosystem quantity and/or quality; (2) [100\%-200\%] indicates an improved ecosystem states. We acknowledge the limitations of selecting a baseline year very close to the policy target, as the rather short time span will not allow for a significant variation of species richness across different climate change scenarios, unless there is an unexpected dramatic climate shock causing extinction of a large number of species. Also, an increase in species richness may not imply an increase in the environmental quality, but may be caused by adding invasive species that are damages to the local ecosystem. Nonetheless, our calculation can still be useful in the context of policymaking, especially when immediate decisions need to be made for preventing endangered species from extinction under warming weather conditions or when appraisals are required for projects that may affect interactions between climate change and ecosystem services.

In the present study, a NCI-like indicator is constructed to describe the change of overall ecosystem under different IPCC scenarios. Similar to the NCI approach, ecosystem quality is calculated as ratio between projected species richness of different future storylines in 2050 and that of the baseline year 2000. The ecosystem quality contains information of four core species, including tree, plant, bird and herptile for the selected 17 European countries. Ecosystem quantity is the percentage of forest habitat in a country's total area. Figure 2 presents a flow chart showing how the NCI-like biodiversity indicator is constructed. 


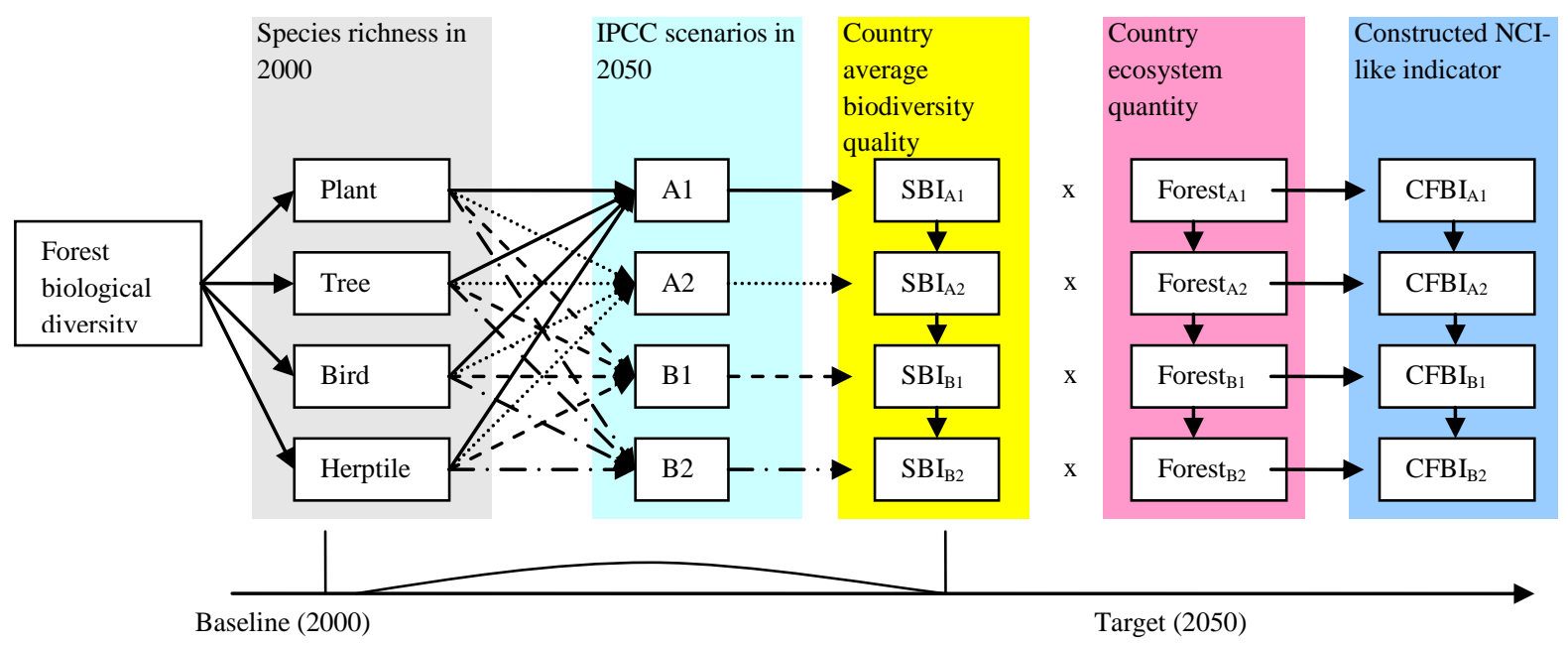

Figure 2 Constructing a NCI-like indicator to estimate the trend of biodiversity in future IPCC scenarios (note: SBI refers to the aggregated average score of species richness of plant, tree, bird and herptile species.)

The construction of aggregated NCI-like indicator encompasses two steps.

The first step is to compute the average changes of ecosystem quality in the future under different climate change scenarios. For each country, the change of individual species under future climate change scenarios is expressed as the ratio between species richness of the species in 2050 and that of the baseline. Furthermore, we aggregated individual percentage changes of species richness for tree, plant, bird and herptile to get a country average score, which describes the changes of country's ecosystem quality under each IPCC scenario with respect to the baseline.

The second step is to construct a NCI-like indicator, a composite indicator, which aggregates information regarding future qualitative and quantitative changes of biodiversity with respect to the baseline. We name it as Composite Forest Biodiversity Indicator (CFBI), which is the product of percentage changes of forest quality (calculated in step 1) and the percentage changes of forest area in 2050 with respect to the baseline under different IPCC storylines. Thus, the computed CFBI score also reflects the direct impacts of land-use changes on biodiversity. In particular, the expansion of forest area in many parts of Europe may have a positive impact on the CFBI score.

The calculated CFBI scores for the EU-17 under four different IPCC scenarios are presented in Figure 3 below. 


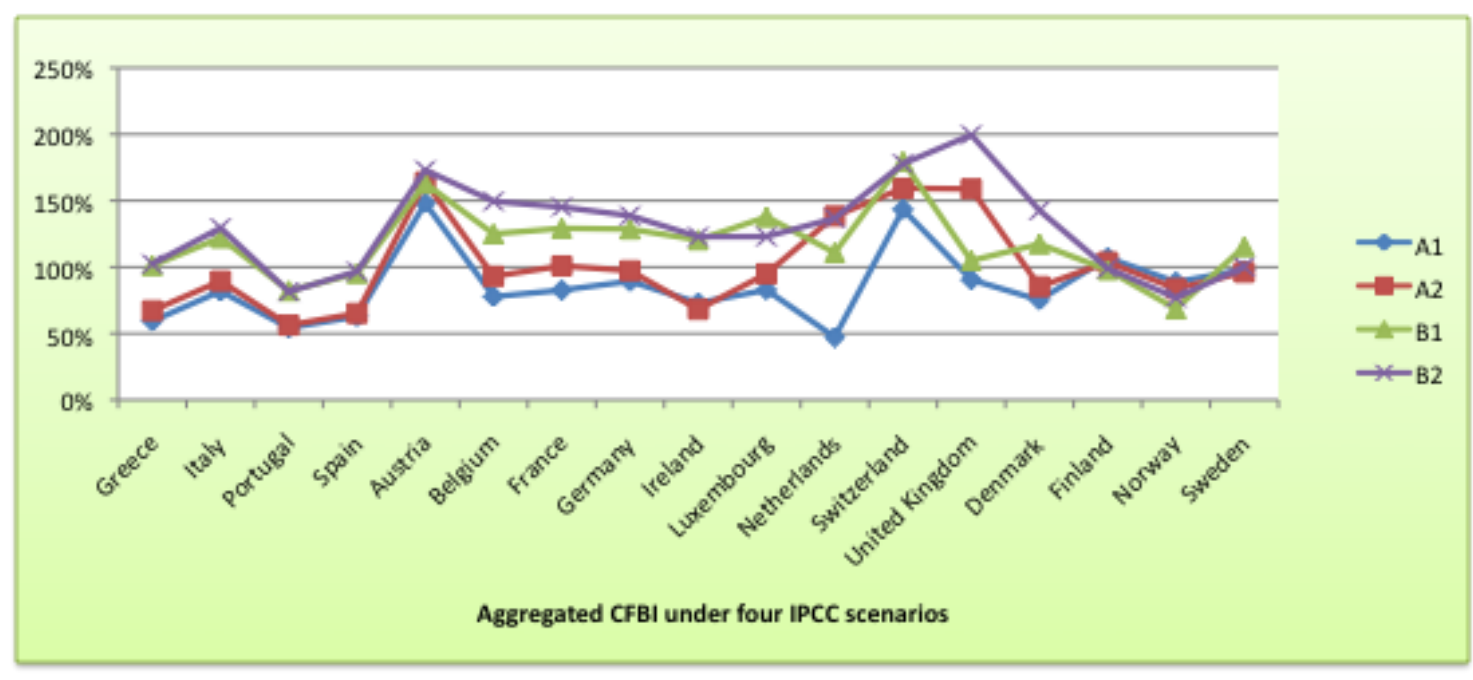

Figure 3. Computed CFBI score for the EU-17 under four IPCC storylines.

As we have mentioned above, the CFBI score ranges between two intervals: [0-100\%] and [100\%-200\%]. If the CFBI falls between [0,100\%], it illustrates that a country's forest ecosystem has deteriorated under climate change scenarios because of the reduction of forest area as a result of land use competition for economic development, and/or because of the decreased quality of biodiversity in the country, or because of a combination of the both causes. If the CFBI score falls between [100\%$200 \%$ ], it shows on average an overall improved forest ecosystem. However, the reason of such improvement is not straightforward. It may not be necessarily caused by the increase in species richness of the selected four species in the next decades, but may be due to the extended ecosystem coverage as a result of some effective environmental policy regimes of the country, such as increased forest area due to reforestation activities. Moreover, it is also important to note that a CFBI score greater than $100 \%$ does not necessarily mean the local species are not under threats, rather it indicates an overall improvement of the ecosystems due to compensation between different aspects of biodiversity. Thus, to better interpret the CFBI score, we need to look closely at the national/regional forest management policies and their effectiveness.

In Figure 3, the CFBI score shows that if moving towards the economic oriented development paths, as represented by the A1 and A2 scenarios, we will most likely observe a worsen status of forest ecosystem across Europe owing to increased pressures from economic development, population growth, severer increase of average temperature and land-use conversion. Among all others, the warmer region, i.e. Mediterranean Europe suffers the most loss of biodiversity quantity and quality in both scenarios compared to the colder regions. On the contrary, the environmental oriented development paths, as represented by B1 and B2 scenarios, show a significant improvement in the forest status in most of the European countries, except Greece, Portugal, Spain, Finland, Norway and Sweden. This implies that the adoption of sustainable forest management practices in Europe is successful in general. However, given the relatively high reference level of forest management in the Scandinavian countries in the baseline year, we will not foresee significant improvement in forest quantity and quality over the next 40 years, independent from the future standpoints. Whereas in the Mediterranean countries, although the resources management in practice are considered less efficient than those of Northern European countries, we can still observe a general improvement of the forest status owing to the sustainable management of natural resources, slowing down population growth, improving sectoral productivities and energy efficiency, and reducing land conversion. 


\section{The econometric model}

\subsection{The hypotheses and model specification}

It is assumed that climate change disturbance through biodiversity and ecosystem functioning will impose an impact, most probably a negative one, on human welfare, the objective of our model is therefore to explicitly assess this complex interaction and then estimate the marginal effects of climate change induced biodiversity loss on the value of ecosystem services. This assumption implies a number of hypotheses that we would like to test using the econometric model:

(1) Climate change, here expressed as increase in temperature, will alter the pattern of biodiversity distribution and species richness presented in a geographical region, which is measured by the composite forest biodiversity indicator (CFBI). In particular, we want to test whether increases in temperature will have effects over the biodiversity indicators that are ecosystem service specific and spatially different.

(2) The climate change induced CFBI changes will further affect the ecosystem's ability of providing goods and services and their respective values. Similarly, this effect is also expected to vary across geo-climatic regions and the types of ecosystem services under consideration.

To capture the complex relationships between biodiversity, ecosystem and human welfare, we propose to solve the problem in a simultaneous equation system using 3SLS (three-stage-leastsquares) regression, which is considered consistent and more efficient than a linear approximation in this respect (Verbeek, 2000). In particular, the simultaneous structural system contains following three equations:

$$
\begin{aligned}
& E q .(1) \\
& \ln \left(E V_{i}\right)=\beta_{10_{i}}+\beta_{11 i} \ln (f a)+\beta_{12 i} \ln (t)+\beta_{13 i} C F B I+\beta_{14 i} C F B I \_t+\varepsilon_{11 i}
\end{aligned}
$$

Eq. (2)

$$
\ln (f a)=\beta_{20}+\beta_{21} \ln (G D P)+\beta_{22} \ln (t)+\beta_{23} \ln (\text { pop_dens })+\varepsilon_{21}
$$

Eq. (3)

$$
C F B I=\beta_{30}+\beta_{31} t+\beta_{32} t^{2}+\beta_{33} n t s+\beta_{34} n b s+\beta_{35} n p s+\beta_{36} n h s+\beta_{37} \ln \left(p o p \_d e n\right)+\beta_{38} \ln (G D P)+\varepsilon_{31}
$$

where

$C F B I=$ Composite Forest Biodiversity Indicator (\%)

$t=$ increased Celsius degrees of local temperature by 2050 under future IPCC scenarios

$f a=$ projected forest area (million ha) in 2050 under future IPCC scenarios

Pop_dens $=$ projected population density (heads/ha) in 2050 under IPCC scenarios

$G D P=$ projected gross domestic production (billion \$) in 2050 under IPCC scenarios

$E V=$ economic value of ecosystem service $i$ (in million \$) estimated for 2050 under IPCC scenarios

$n t s=$ number of tree species projected in 2050 under IPCC scenarios

$n b s=$ number of bird species projected in 2050 under IPCC scenarios

$n p s=$ number of plant species projected in 2050 under IPCC scenarios

$n h s=$ number of herptile species projected in 2050 under IPCC scenarios

We assume that $E V, C F B I$ and $f a$ are endogenous variables in the system and $\varepsilon_{1}, \varepsilon_{2}$ and $\varepsilon_{3}$ are the stochastic disturbance terms that capture all unobservable factors that may influence the dependent 
variables. In the first two equations, all variables, except $C F B I$ are in their log-transformations indicate that the estimated beta coefficients measure the elasticity of dependent variables with respect to the changes in a set of explanatory variables. As for the warming impact on biodiversity, it is estimated using equation (3) by regressing $C F B I$ on temperature variables ( $t$ and $t^{2}$ ), along with other biological and socio-economic variables that may explain the trends of biodiversity changes in the future scenarios. In particular, the temperature variable $t$ will capture the marginal impact of climate change on biodiversity with increment of $1^{\circ} \mathrm{C}$ in the temperature and the squared $t$ is introduced to capture the rate of this change. In Table 2, we summarize the descriptive statistics of all the variables. For each variable, we have four observations under four IPCC storylines for total 17 countries under consideration, which gives rise to total 68 observations.

\begin{tabular}{|c|c|c|c|c|c|}
\hline Variables & Obs & Mean & $\begin{array}{l}\text { Std. } \\
\text { Dev. }\end{array}$ & Min & Max \\
\hline Forest area (fa) & 68 & 7.02 & 7.36 & 0.07 & 25.88 \\
\hline Population density (pop_dens) & 68 & 1.24 & 1.02 & 0.08 & 3.33 \\
\hline GDP & 68 & 1110.28 & 1310.00 & 22.38 & 5569.02 \\
\hline Number of tree species (nts) & 68 & 38.42 & 13.51 & 10.96 & 70.96 \\
\hline Number of bird species (nbs) & 68 & 130.26 & 13.58 & 106.47 & 154.31 \\
\hline Number of plant species (nps) & 68 & 259.64 & 36.52 & 199.61 & 361.78 \\
\hline Number of herptile spcies (nhs) & 68 & 20.00 & 11.04 & 1.72 & 39.39 \\
\hline The composite biodiversity indicator (cfbi) & 68 & 1.08 & 0.34 & 0.47 & 2 \\
\hline Temperature $(\mathrm{t})$ & 68 & 3.69 & 1.22 & 1.5 & 6.9 \\
\hline $\begin{array}{l}\text { Economic value of provisioning services } \\
\left(\mathrm{EV}_{\mathrm{PS}}\right)\end{array}$ & 68 & 4776.07 & 5214.79 & 100.95 & 17600 \\
\hline Economic value of cultural services $\left(\mathrm{EV}_{\mathrm{CS}}\right)$ & 68 & 454.07 & 568.80 & 3.13 & 2615.14 \\
\hline Economic value of regulating services $\left(\mathrm{EV}_{\mathrm{RS}}\right)$ & 68 & 2041.77 & 2023.33 & 71.39 & 7465.75 \\
\hline
\end{tabular}

Next, we proceed with a 3SLS regression which allows us to estimate simultaneously (1) the determinants of economic value of ecosystem services; (2) the determinants of land-use changes (i.e. the changes of forest land cover); (3) the determinants of changes in biodiversity.

More specifically, in Equation (1), we attempt to explain the economic value of ecosystem services as a function of forest area, increases of temperature and biodiversity conditions. We simultaneously test the hypotheses that enlarged forest area and improved biodiversity condition will positively affect the ecosystem values, whereas rising temperature may have a negative impact.

Equation (2) attempts to explain the land-use change, as expressed by the enlarged or shrunk forest area in the model, is mainly driven by socio-economic and demographics variables of the country. Especially, we expect that higher level of GDP generated in the EU member states in the future scenarios will drive the increase of demand for forest related products and services, in particular, in terms of an improved forest quality and increased forest coverage. Thus the desire for a better natural environment will trigger the reinforcement of sustainable management policies to conserve natural habitats and forest biodiversity. On the contrary, the mounting populations projected in future scenarios will increase the pressure on the natural area by converting natural forests to agricultural land or human settlement. In the meanwhile, we also assume that temperature may have a role in affecting the forest natural regeneration process, but direction of its impact on forest area is ambiguous. 
Finally, Equation (3) attempts to test statistically whether the RHS variables, such as rising temperature, changes of species richness in a set of key species, and changes of socio-economic and demographic conditions under different climate change scenarios can influence the dependent variable $C F B I$, which measures the general improvement or degradation of biodiversity quality and quantity corresponding to each of the projected future states. Especially, we are interested in whether warmer conditions will negatively affect forest biodiversity across regions, as well as the ecosystem's ability of providing ecosystem goods and services and their respective values. Moreover, high population density and continual economic growth are expected to impose high pressure on biodiversity through intensive conversion of land from natural forests to other land-uses and therefore negatively affect biodiversity quality and quantity.

\subsection{SLS results}

Given the baseline model specification above, we first run 3SLS regression in a global condition, in which all data are pooled together without considering the different spatial effects of climate change. Later, we will modify the baseline model in order to capture the specific impact of climate change on each of the three geo-climatic regions, i.e. Mediterranean Europe, Central Europe and Scandinavian Europe. However, due to the nature of ecosystem values varies depending on the types of ecosystem services under consideration, we shall treat the three types of values differently.

\section{(1) Estimating the global effects using the baseline model}

Table 3 below reports the 3SLS results of the baseline model. The goodness of the linear approximation in the structural simultaneous system was assessed based on the coefficients of determination $\left(R^{2}\right)$. For almost all equations, the estimated $R^{2}(>0.5)$ with $P>0.0000$ suggest the goodness of fit of the performed regression. Independent from the type of ecosystem service, most of all estimated beta coefficients carry the expected sign.

In particular, in equation (1), it shows that the value of forest ecosystem services is statistically significantly related to the forest size. That is every additional hectare of forest will lead to proportional increases in values for all ecosystem services, and the marginal effects range from $67 \%$ on provisioning service to more than $100 \%$ on cultural service. Moreover, the estimated coefficients of biodiversity variable are statistically significant for all ecosystem services indicating a significant impact of biodiversity on the value of ecosystem services, however the direction of the impact is vague. For instance, the composite biodiversity indicator is found positive and statistically significantly correlated with the provisioning and regulating services, but cultural service. We suspect this is due to the fact that pooling data across geo-climatic regions may mess us the different spatial effects of climate change imposed on biodiversity at regional level. We shall treat this problem later in a modified regional model specification. Finally, as expected, all ecosystem values are found sensitive to the change of temperature. That is to say, every $1^{\circ} \mathrm{C}$ increase in temperature will contribute proportionally to the changes of the value of ecosystem services. In particular, the impact of rising temperature is positive on the value of provisioning and regulating services may be corresponding to the scientific discovery that the changing climate can increase forest productivity and also carbon stock in the boreal forest ecosystem in Scandinavian Europe at least in the short run (Garcia-Gonzalo et al., 2007). Nevertheless, the warming condition will negatively decrease the cultural value provided by European forests as a whole due to the diminishing cultural value generated in Mediterranean forests, where higher recreational values are usually found, as these forests will suffer from warming temperature and lower precipitation rate. 
Table 3. 3SLS results of the baseline model - global effects

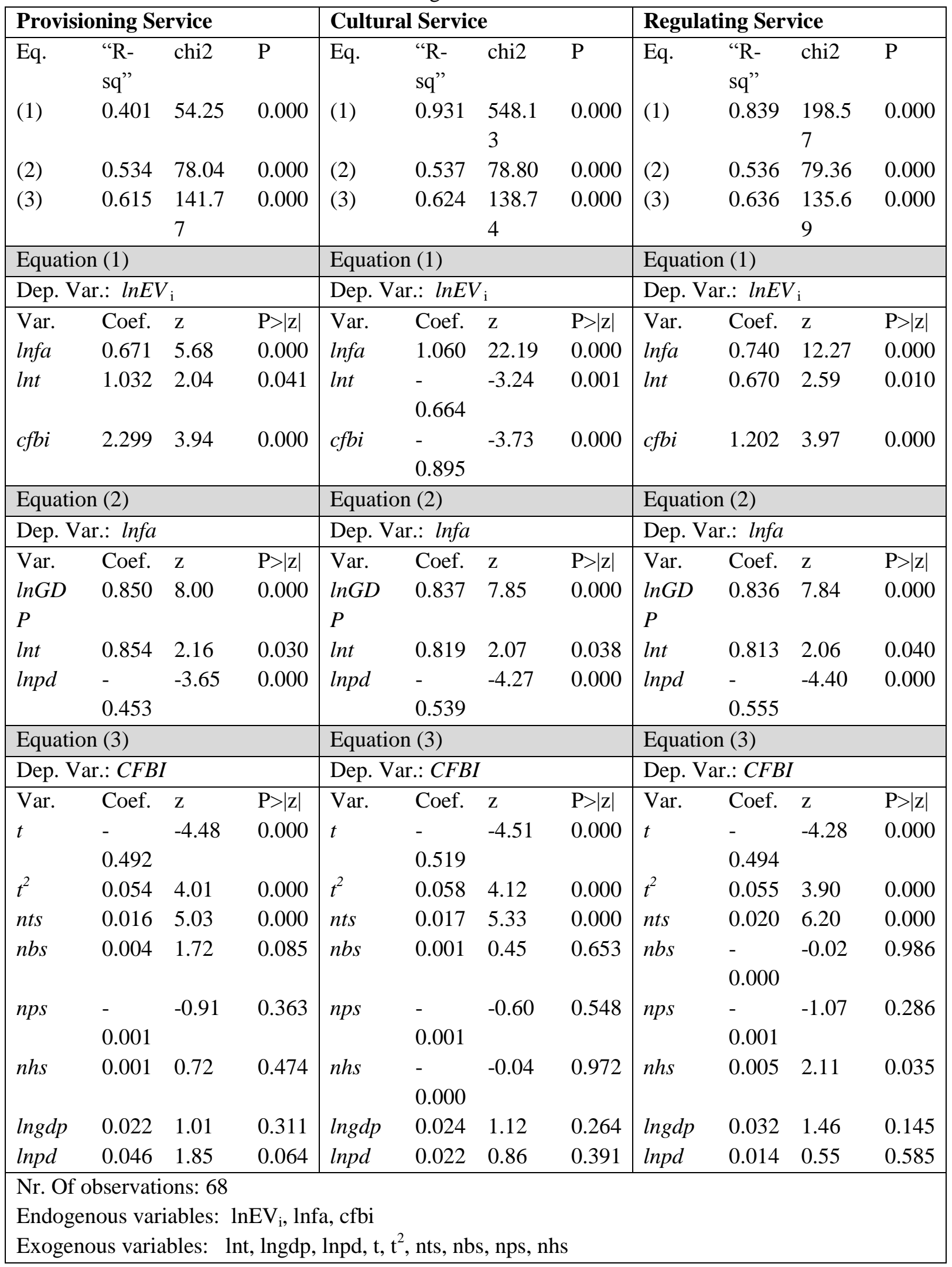

Furthermore, Equation (2) shows that all selected explanatory variables are statistically significantly related to land-use changes. The estimated coefficients of each variable are found similar across all ecosystem services, suggesting the robustness of our results. Our results suggest that 
increases in GDP and rising temperature contribute proportionally to the extension of forest areas. As argued previously, our desire for a better natural environment is increased along with our growing wealth, whereas the positive impact of climate change on forest area may imply the effectiveness of sustainable forest management practices that promote deforestation activities and encourage the enlarged plantations in most of the EU-17 countries. Finally, the negative coefficients of population density under all ecosystem services indicate the mounting population in the future state will impose greater pressure on forest land and may lead to the conversion of protected forest area to other land uses such as human settlement.

Finally, in Equation (3), we detect clearly a negative impact of rising temperature on the composite biodiversity indicator at increasing rate. In other words, our finding suggests that forest biodiversity is already suffering from the warm temperature in Europe and the continual changes in temperature will worsen the situation. Moreover, the beta coefficients of temperature variables are found consistent across ecosystem services, suggesting the robustness of our results. In addition, the increase of every additional tree species, among other things, contributes proportionally to $1 \%$ increase in the score of the composite biodiversity indicator. In contrast, the richness of other species is not statistically correlated with forest biodiversity indicator, so as the two socio-economic variables (GDP and population density).

\section{(2) Estimating the regional effects using a modified model specification}

In order to further test the hypothesis that climate change imposes different regional effects on biodiversity indicator and thus the respective value of ecosystem services, i.e. the climate change induced biodiversity effect on ecosystem service values, we introduce a cross-effect between $C F B I$ and regional temperature variables to generation a matrix of $C F B I_{-} T_{\text {region }}$ that contains three regional specific $C F B I$ variables and substitute $C F B I$ in Equation (1) with this new matrix. This is to capture the indirect impact of climate change on the value of ecosystem services. Furthermore, we modify Equation (3) by substituting the temperature variable with a matrix of regional temperature variables, $t_{\text {region}}$, which allows us to differentiate impacts of rising temperature at different geographical locations. As a result, we obtain a modified structural simultaneous system below. Now, we will repeat the regression analysis using 3SLS in this modified structural system.

Eq. (4)

$$
\ln \left(E V_{i}\right)=\beta_{10_{i}}+\beta_{11 i} \ln (f a)+\beta_{12 i} \ln (t)+\beta_{13 i} C F B I_{-} T_{\text {region }}+\varepsilon_{11 i}
$$

Eq. (5)

$$
\ln (f a)=\beta_{20}+\beta_{21} \ln (G D P)+\beta_{22} \ln (t)+\beta_{23} \ln \left(p o p \_d e n s\right)+\varepsilon_{21}
$$

Eq. (6)

$$
C F B I=\beta_{30}+\beta_{31} t_{\text {region }}+\beta_{32} t^{2}+\beta_{33} n t s+\beta_{34} n b s+\beta_{35} n p s+\beta_{36} n h s+\beta_{37} \ln \left(p o p \_d e n\right)+\beta_{38} \ln (G D P)+\varepsilon_{31}
$$

The 3SLS regression results are presented in Table 4. The goodness of the linear approximation in the structural simultaneous system was assessed based on the coefficients of determination $\left(\mathrm{R}^{2}\right)$. Comparing to the baseline model, we see that the introduction of regional effects improves significantly the goodness of fits of the performed regression. Moreover, the new model result again shows that one-hectare increase of forest area is statistically significantly correlated to every one-dollar increase in the value of all ecosystem services.

As for the spatial effects of climate change, our results are promising. First of all, three new explanatory variables $c f b i_{-} t s, c f b i_{-} t m$ and $c f b i_{-} t c$ are introduced in Equation (4) to count for the indirect/induced impacts of climate change on ecosystem service values through the altered 
biodiversity across three geo-climatic regions: i.e. the Scandinavian Europe, Mediterranean Europe, and Central-Northern Europe, respectively. By comparing these coefficients with the coefficient of lnt, which captures the direct effects of rising temperature on the value of ecosystem services, we can better understand the dimensions and strength of the cross-effects that affect the ecosystem service values. Moreover, regional temperature effects on biodiversity are captured by the introduction of three temperature variables $t s, t m$ and $t c$ in Equation (6), with represent to temperature changes in the Scandinavian Europe, Mediterranean Europe, and Central-Northern Europe, respectively. These results are particularly useful for interpreting the cross-effects of biodiversity and temperature in Equation (4) and understanding the climate change induced biodiversity effect on the overall value of ecosystem services. In general, our results show that changing climate will accelerate biodiversity loss across all three geo-climatic regions (see the results of equation (6)), and these changes may impose even further impacts on the values of all ecosystem services provided by different forest ecosystems (see the results of equation (4)), but the directions and magnitudes of these impacts are mixed, depending on the nature of the ecosystem services under consideration. All in all, we can observe two opposite cross-effects of biodiversity and temperature on the value of ecosystem service values.

Table 4. 3SLS results of the modified model - regional effects

\begin{tabular}{|c|c|c|c|c|c|c|c|c|c|c|c|}
\hline \multicolumn{4}{|c|}{ Provisioning Service } & \multicolumn{4}{|c|}{ Cultural Service } & \multicolumn{4}{|c|}{\begin{tabular}{|l|} 
Regulating Service \\
\end{tabular}} \\
\hline Eq. & $\begin{array}{l}\text { "R- } \\
\text { sq" }\end{array}$ & chi2 & $\mathrm{P}$ & Eq. & $\begin{array}{l}\text { "R- } \\
\text { sq" }\end{array}$ & chi2 & $\mathrm{P}$ & Eq. & $\begin{array}{l}\text { "R- } \\
\text { sq" }\end{array}$ & chi2 & $\mathrm{P}$ \\
\hline \multirow[t]{2}{*}{ (1) } & 0.58 & 111.1 & 0.00 & (1) & 0.98 & 3704.4 & 0.00 & $(1)$ & 0.87 & 345.8 & 0.00 \\
\hline & 2 & 6 & 0 & & 5 & 7 & 0 & & 4 & 5 & 0 \\
\hline \multirow[t]{2}{*}{ (2) } & 0.53 & 77.07 & 0.00 & (2) & 0.53 & 79.38 & 0.00 & $(2)$ & 0.53 & 79.37 & 0.00 \\
\hline & 3 & & 0 & & 7 & & 0 & & 7 & & 0 \\
\hline \multirow[t]{2}{*}{ (3) } & 0.64 & 154.2 & 0.00 & (3) & 0.64 & 152.49 & 0.00 & (3) & 0.64 & 157.0 & 0.00 \\
\hline & 3 & 5 & 0 & & 3 & & 0 & & 2 & 7 & 0 \\
\hline \multicolumn{4}{|c|}{ Equation (4) } & \multicolumn{4}{|c|}{ Equation (4) } & \multicolumn{4}{|c|}{ Equation (4) } \\
\hline \multicolumn{4}{|c|}{ Dep. Var.: $\ln E V_{\mathrm{i}}$} & \multicolumn{4}{|c|}{ Dep. Var.: $\ln E V_{\mathrm{i}}$} & \multicolumn{4}{|c|}{ Dep. Var.: $\ln E V_{\mathrm{i}}$} \\
\hline Var. & $\begin{array}{l}\text { Coef } \\
\text {. }\end{array}$ & $\mathrm{z}$ & $\mathrm{P}>|\mathrm{z}|$ & Var. & $\begin{array}{l}\text { Coef } \\
\text {. }\end{array}$ & $\mathrm{z}$ & $\mathrm{P}>|\mathrm{z}|$ & Var. & $\begin{array}{l}\text { Coef } \\
\text {. }\end{array}$ & $\mathrm{z}$ & $\mathrm{P}>|\mathrm{z}|$ \\
\hline $\ln f a$ & $\begin{array}{l}0.86 \\
3\end{array}$ & 8.19 & $\begin{array}{l}0.00 \\
0\end{array}$ & $\operatorname{lnfa}$ & $\begin{array}{l}1.01 \\
1\end{array}$ & 43.18 & $\begin{array}{l}0.00 \\
0\end{array}$ & $\ln f a$ & $\begin{array}{l}0.76 \\
9\end{array}$ & 13.50 & $\begin{array}{l}0.00 \\
0\end{array}$ \\
\hline $\ln t$ & $\begin{array}{l}0.19 \\
3\end{array}$ & 0.41 & $\begin{array}{l}0.68 \\
0\end{array}$ & $\ln t$ & $\begin{array}{l}- \\
0.29 \\
0\end{array}$ & -2.77 & $\begin{array}{l}0.00 \\
6\end{array}$ & $\ln t$ & $\begin{array}{l}- \\
0.15 \\
6\end{array}$ & -0.62 & $\begin{array}{l}0.53 \\
6\end{array}$ \\
\hline$c f b i \_t s$ & $\begin{array}{l}- \\
0.04 \\
1\end{array}$ & -0.27 & $\begin{array}{l}0.78 \\
6\end{array}$ & $c f b i \_t s$ & $\begin{array}{l}- \\
0.05 \\
9\end{array}$ & -1.74 & $\begin{array}{l}0.08 \\
2\end{array}$ & cfbi_ts & $\begin{array}{l}0.08 \\
5\end{array}$ & 1.04 & $\begin{array}{l}0.29 \\
6\end{array}$ \\
\hline $\begin{array}{l}c f b i \_t \\
m\end{array}$ & $\begin{array}{l}- \\
0.49 \\
3\end{array}$ & -2.50 & $\begin{array}{l}0.01 \\
2\end{array}$ & $\begin{array}{l}c f b i \_t \\
m\end{array}$ & $\begin{array}{l}0.27 \\
9\end{array}$ & 6.31 & $\begin{array}{l}0.00 \\
0\end{array}$ & $\begin{array}{l}c f b i \_t \\
m\end{array}$ & $\begin{array}{l}0.25 \\
1\end{array}$ & 2.38 & $\begin{array}{l}0.01 \\
8\end{array}$ \\
\hline$c f b i \_t c$ & $\begin{array}{l}0.06 \\
2\end{array}$ & 0.57 & $\begin{array}{l}0.57 \\
1\end{array}$ & $c f b i \_t c$ & $\begin{array}{l}- \\
0.02 \\
7\end{array}$ & -1.10 & $\begin{array}{l}0.27 \\
2\end{array}$ & $c f b i \_t c$ & $\begin{array}{l}0.25 \\
9\end{array}$ & 4.38 & $\begin{array}{l}0.00 \\
0\end{array}$ \\
\hline Equatio & (5) & & & Equatio & (5) & & & Equatio & (5) & & \\
\hline Dep. Va & $\therefore \ln f a$ & & & Dep. Va & $\therefore: \ln f a$ & & & Dep. V & $\therefore \ln f a$ & & \\
\hline Var. & Coef & $\mathrm{z}$ & $\mathrm{P}>|\mathrm{z}|$ & Var. & Coef & $\mathrm{Z}$ & $\mathrm{P}>|\mathrm{z}|$ & Var. & Coef & $\mathrm{Z}$ & $\mathrm{P}>|\mathrm{z}|$ \\
\hline
\end{tabular}




\begin{tabular}{|c|c|c|c|c|c|c|c|c|c|c|c|}
\hline $\ln G D P$ & $\begin{array}{l}0.84 \\
4\end{array}$ & 7.94 & $\begin{array}{l}0.00 \\
0\end{array}$ & $\ln G D P$ & $\begin{array}{l}0.84 \\
6\end{array}$ & 7.93 & $\begin{array}{l}0.00 \\
0\end{array}$ & $\ln G D P$ & $\begin{array}{l}0.83 \\
8\end{array}$ & 7.89 & $\begin{array}{l}0.00 \\
0\end{array}$ \\
\hline \multirow[t]{2}{*}{$\operatorname{lnt}$} & 0.85 & 2.18 & 0.03 & $\ln t$ & 0.82 & 2.08 & 0.03 & $\ln t$ & 0.82 & 2.08 & 0.03 \\
\hline & 9 & & 0 & & 1 & & 8 & & 0 & & 8 \\
\hline \multirow[t]{3}{*}{$\operatorname{lnpd}$} & - & -3.56 & 0.00 & $\operatorname{lnpd}$ & - & -4.14 & 0.00 & lnpd & - & -4.26 & 0.00 \\
\hline & 0.44 & & 0 & & 0.52 & & 0 & & 0.53 & & 0 \\
\hline & 6 & & & & 4 & & & & 2 & & \\
\hline \multicolumn{4}{|c|}{ Equation (6) } & \multicolumn{4}{|c|}{ Equation (6) } & \multicolumn{4}{|c|}{ Equation (6) } \\
\hline \multicolumn{4}{|c|}{ Dep. Var.: $C F B I$} & \multicolumn{4}{|c|}{ Dep. Var.: $C F B I$} & \multicolumn{4}{|c|}{ Dep. Var.: $C F B I$} \\
\hline Var. & Coef & $\mathrm{z}$ & $\mathrm{P}>|\mathrm{z}|$ & Var. & Coef & $\mathrm{z}$ & $\mathrm{P}>|\mathrm{z}|$ & Var. & Coef & $\mathrm{z}$ & $\mathrm{P}>|\mathrm{z}|$ \\
\hline \multirow[t]{3}{*}{ ts } & - & -4.68 & 0.00 & ts & - & -4.70 & 0.00 & $t s$ & - & -4.46 & 0.00 \\
\hline & 0.53 & & 0 & & 0.53 & & 0 & & 0.50 & & 0 \\
\hline & 6 & & & & 8 & & & & 3 & & \\
\hline \multirow[t]{3}{*}{ tc } & - & -4.40 & 0.00 & $t c$ & - & -4.40 & 0.00 & $t c$ & - & -4.19 & 0.00 \\
\hline & 0.51 & & 0 & & 0.51 & & 0 & & 0.48 & & 0 \\
\hline & 3 & & & & 4 & & & & 3 & & \\
\hline \multirow[t]{3}{*}{$\mathrm{tm}$} & - & -4.73 & 0.00 & $\mathrm{tm}$ & - & -4.76 & 0.00 & $\mathrm{tm}$ & - & -4.61 & 0.00 \\
\hline & 0.57 & & 0 & & 0.57 & & 0 & & 0.55 & & 0 \\
\hline & 5 & & & & 8 & & & & 3 & & \\
\hline \multirow[t]{2}{*}{$t^{2}$} & 0.06 & 4.27 & 0.00 & $t^{2}$ & 0.06 & 4.29 & 0.00 & $t^{2}$ & 0.05 & 4.07 & 0.00 \\
\hline & 1 & & 0 & & 1 & & 0 & & 7 & & 0 \\
\hline \multirow[t]{2}{*}{$n t s$} & 0.01 & 5.11 & 0.00 & $n t s$ & 0.01 & 5.11 & 0.00 & $n t s$ & 0.01 & 5.44 & 0.00 \\
\hline & 7 & & 0 & & 7 & & 0 & & 8 & & 0 \\
\hline \multirow[t]{3}{*}{$n b s$} & - & -0.43 & 0.66 & $n b s$ & - & -0.60 & 0.55 & $n b s$ & - & -0.65 & 0.51 \\
\hline & 0.00 & & 9 & & 0.00 & & 0 & & 0.00 & & 3 \\
\hline & 1 & & & & 1 & & & & 1 & & \\
\hline \multirow[t]{3}{*}{$n p s$} & - & -0.42 & 0.67 & nps & - & -0.38 & 0.70 & $n p s$ & - & -0.57 & 0.57 \\
\hline & 0.00 & & 4 & & 0.00 & & 2 & & 0.00 & & 0 \\
\hline & 0 & & & & 0 & & & & 1 & & \\
\hline \multirow[t]{2}{*}{$n h s$} & 0.00 & 1.73 & 0.08 & nhs & 0.00 & 1.72 & 0.08 & nhs & 0.00 & 2.11 & 0.03 \\
\hline & 7 & & 3 & & 7 & & 6 & & 9 & & 5 \\
\hline \multirow[t]{2}{*}{$\ln g d p$} & 0.03 & 1.56 & 0.11 & $\ln g d p$ & 0.03 & 1.64 & 0.10 & $\operatorname{lng} d p$ & 0.03 & 1.69 & 0.09 \\
\hline & 5 & & 9 & & 7 & & 2 & & 8 & & 1 \\
\hline \multirow[t]{3}{*}{$\operatorname{lnpd}$} & - & -0.28 & 0.78 & $\operatorname{lnpd}$ & - & -0.57 & 0.56 & $\operatorname{lnpd}$ & - & -0.71 & 0.47 \\
\hline & 0.00 & & 1 & & 0.01 & & 6 & & 0.02 & & 7 \\
\hline & 8 & & & & 8 & & & & 2 & & \\
\hline \multicolumn{12}{|c|}{ Nr. Of observations: 68} \\
\hline Endoge & & & & & & & & & & & \\
\hline 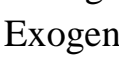 & & Ac. & & & & & & & & & \\
\hline
\end{tabular}

On the one hand, our results reveal that biodiversity and temperature are "complimentary" factors affecting the supply of EGS in a given geo-climatic region, and therefore for this region the climate change induced biodiversity loss may increase the overall negative impacts. This is particularly clear in the case of provisioning services provided by Mediterranean forests. Our results suggest that the negative impacts of climate change on biodiversity will go against the positive direct climate change impact on the Mediterranean forests, and generate a net negative impact on total value 
of provisioning services in the future. More specifically, biodiversity loss caused by increment of $1^{\circ} \mathrm{C}$ in the temperature is responsible for at least $49 \%$ in every one-dollar reduction of the value of forest provisioning service in the Mediterranean forests. This finding is consistent with some of the previous studies. For instance, Linder et al. (2008) has found that climate change may reduces the forestry productivity in the Mediterranean region in the future, as warming will be greatest over western and southern Europe in summer, substantially affect the precipitation rate and increase the risk of extreme weather events, such as prolonged drought, storms and floods in the area. Moreover, in a different geographical context, Costanza et al. (2007) also found a strong positive relationship between biodiversity and ecosystem productivity in higher temperature regimes in the United States. However, the cross-effects of biodiversity and temperature are not statistically significant for the remaining two geo-climatic regions. To better understand the underlying reasons of this result, further investigation is needed.

On the other hand, biodiversity and temperature can also serve as "substitute" factors that determine some of ecosystem service values under consideration. This is to say, the climate change induced biodiversity impacts on EGS may attenuate/decrease the negative direct climate change impact in some regions, where biodiversity plays a key role in mitigating the those negative impacts of climate change. For instance, this is clear for the cultural services provided by the Mediterranean forests, in which the reduction of $1{ }^{\circ} \mathrm{C}$ in the temperature is responsible for half of every $1 \%$ improvement of biodiversity indicator score. The latter will consequently contribute to nearly $28 \%$ of every additional one-dollar value generated in the cultural services provided by Mediterranean forests. Similar result is found also for the regulating services in the region, where biodiversity richness is expected to have a significant role in determining the respective values. In conclusion, our result suggests that although climate change may have directly negative impacts on the value of ecosystem services, it is possible to mitigate these negative impacts by better managing biodiversity and natural resources. In many cases, the benefits derived from biodiversity can be large enough to compensate the loss of ecosystem productivities and values as a result of climate change.

\section{Concluding remarks and further research}

This paper attempted to model the relationships between climate change, biodiversity and the value of ecosystem services with a specific emphasis on the climate change included biodiversity effects in European forests. The research begun with the construction of a composite biodiversity indicator that integrated quantitative and qualitative changes of biodiversity projected under different future climate scenarios. This indicator incorporated in-depth socio-economic reasons of biodiversity changes, along with climate change impacts was expected to be a simple but comprehensive biodiversity measure to analyze the climate change induced biodiversity effects and the resulting socio-economic impacts. In the present study, we tried to make the best use of existing data released by a large number of IPCC data distribution centers, regarding the projected trends of population growth, economic development, future species richness and increase in local temperature under different future climate scenarios. Values of ecosystem services were derived from a most recent assessment study on the climate change impacts on forest ecosystems in Europe (Ding et al. 2010). Furthermore, the paper explored the use of 3SLS regression to simultaneously estimate (1) the determinants of economic value of ecosystem services; (2) the determinants of land-use changes (i.e. the changes of forest-land cover); (3) the determinants of changes in biodiversity. The investigation was conducted first in a baseline model, where a global effect of climate change was considered, followed by regressing a modified model, in which the regional effects of climate change impacts were counted for. 
To the best of our knowledge, the present paper represents one of the first attempts in the literature to formally model and test the relationship between climate change induced biodiversity loss and the consequent welfare impacts. Despite the data limitation, our preliminary results from a 3SLS regression are promising, confirmed the hypothesis that has been laid out earlier. The consistency of beta coefficients for the same variable across different ecosystem services suggests the robustness of the results.

In summary, the results of the present research suggest that a composite biodiversity indicator, integrating information about changes in species and habitats, can serve as a better option than the individual biodiversity indicators for measuring and predicting the trends of biodiversity changes in response to a set of climate and socio-economic drivers in different future climate change scenarios. For instance, in the present study, the average score of future biodiversity status (reflecting either improvement or degradation of biodiversity) is derived from the projected future trends of four different species, i.e. tree, plant, bird and herptile as well as the changes in forest habitats under different future climate scenarios, therefore the composite biodiversity indicator indicates an overall improvement or degradation of the forest ecosystems in each of the $17 \mathrm{EU}$ member states in a climate change context. In this context, we are more confident to use this indicator to describe and measure the health of forest ecosystems under different climate conditions and to analyze the respective changes in its capacity of delivering ecosystem goods and services. Moreover, the structure of the composite biodiversity indicator is so simple that it can be easily used for communicating with policymakers and the broader audience.

Moreover, our results from the 3SLS regression suggest that rising temperature negatively affects biodiversity and ecosystem conditioning at an accelerating rate across geo-climatic regions in the future. In addition, we also found a strong relationship between temperature and the value of ecosystem services, but the direction of this relationship depends on the type of ecosystem services under consideration. That is to say, every $1^{\circ} \mathrm{C}$ increase in temperature will contribute proportionally to the changes of the value of ecosystem services. Independent from the consideration of spatial effects of climate change, rising temperature is found positively impacting the value of provisioning and regulating services, but negatively related to the cultural services. This result is consistent with some earlier scientific findings (Garcia-Gonzalo et al. 2007), which state that forests in the cold geoclimatic zones, such as the Scandinavian European countries, may benefit from higher temperature in the short run due to the increased forest productivity and carbon stocks in the boreal forests. However, if we take into account the climate change induced biodiversity effects, the direct impact of rising temperature on the value of ecosystem services becomes less clear as a result of interactions between biodiversity and temperature.

In particular, the spatial effect of climate change induced biodiversity changes is captured, by introducing a cross-effect between biodiversity and temperature in the model. All in all, our results show that biodiversity and temperature can perform together as either "complimentary" or "substitute" factors to affect the supply as well as the value of certain types of ecosystem goods and services. In the case of provisioning services provided by Mediterranean forests, we find a clear "complementary" effect between biodiversity and temperature. Our results suggest that the negative impacts of climate change on biodiversity will go against the positive direct climate change impact on the Mediterranean forests, and thus generate a net negative impact on total value of provisioning services in the future. More specifically, biodiversity loss caused by increment of $1^{\circ} \mathrm{C}$ in the temperature is responsible for at least $49 \%$ in every one-dollar reduction of the value of forest provisioning service in the Mediterranean forests. This finding is consistent with some of the previous studies. For instance, Linder et al. (2008) has found that climate change may reduces the forestry productivity in the Mediterranean region in the future, as warming will be greatest over western and southern Europe in summer, substantially affect the precipitation rate and increase the risk of extreme 
weather events, such as prolonged drought, storms and floods in the area. In addition, a similar positive relationship between biodiversity and ecosystem productivity in higher temperature regimes is also found in the US (Costanza et al. 2007). Whereas the substitute effect between biodiversity and temperature refers that climate change induced biodiversity effects on EGS may attenuate/decrease the negative direct climate change impact in some regions, where biodiversity plays a key role in mitigating the those negative impacts of climate change. For instance, this is clear for the cultural services provided by the Mediterranean forests, in which the reduction of $1{ }^{\circ} \mathrm{C}$ in the temperature is responsible for half of every $1 \%$ improvement of biodiversity indicator score. The latter will consequently contribute to nearly $28 \%$ of every additional one-dollar value generated in the cultural services provided by Mediterranean forests. Similar result is found also for the regulating services in the region, where biodiversity richness is expected to have a significant role in determining the respective values.

This result may imply some important synergies of the climate and biodiversity policies. In other words, although climate change may have directly negative impacts on the value of ecosystem services, it is possible to mitigate these negative impacts by better managing biodiversity and natural resources. In many cases, the benefits derived from biodiversity can be large enough to compensate the loss of ecosystem productivities and values as a result of climate change.

However, we are also aware of the limitations in the current study. For instance, the construction of composite biodiversity indicator in this paper is subject to a significant lack of data that covers time-span long enough to describe the evolution of species from the past to the future under different climate change scenarios. As a consequence, we may observe an increase of species richness as well as forest habitats in many countries under the climate change scenarios by 2050 with respect to a baseline year of 2000, owing to the significant efforts of the EU-17 in moving towards more sustainable forest management practice. Thus, it is difficult for us to interpret, to what extent, the projected trends of changes in species richness is a result of the climate change impacts or a combination of different factors. Obviously, there is a need of incorporating more information about species richness from the far distant past into our current database, a large time-span will enable us to rule out many other socio-economic factors other than the direct impact of climate change that affect biodiversity and ecosystem functioning. Finally, a richer historical data can also improve the overall performance of the econometric model and help us to better understand the cross-effects between biodiversity and temperature as well as the pattern in which they affect the ecosystem service values.

\section{References}

Balmford, A., Bennun, L., ten Brink, B., Cooper, D., Côté, I.M., Crane, P., Dobson, A., Dudley, N., Dutton, I., Green, R.E., Gregory, R.D., Harrison, J., Kennedy, E.T., Kremen, C., LeaderWilliams, N., Lovejoy, T.E., Mace, G., May, R., Mayaux, P., Morling, P., Phillips, J., Redford, K., Ricketts, T.H., Rodriguez, J.P., Sanjayan, M, Schei, P.J., van Jaarsveld, A.S., B.A.Walther (2005) "The Converntion on Biological Diversity's 2010 Target”, Science vol 307: 212-213

Baumgärtner S., Becker C., Faber, M., and R. Manstetten (2006) "Relative and Absolute Scarcity of Nature. Assessing the Roles of Economics and Ecology for Biodiversity Conservation", Ecological Economics vol 59: 487-498

Bloger, T. (2001) "The Functional Value of Species Biodiversity: a Review”, Biology and Environment Proceedings of the Royal Irish Academy 101 B (3): 199-224.

Cameron, T. (2002) “2002: The year of the 'Diversity-Ecosystem Function' debate”, TRENDS in Ecology \& Evolution Vol. 17 (11): 495-496 
Chiabai, A. Travisi, C., Markandya, A., Ding, H. and P.A.L.D. Nunes (forthcoming) "Economic Assessment of Forest Ecosystem Services Losses: Cost of Policy Inaction", Journal of Environmental and Resource Economics

Christie M., Warren J., Hanley, N., Murphy, K., Wright, R., Hyde, T. and N. Lyons (2004)

"Developing measures for valuing changes in biodiversity: Final report", Report to DEFRA London.

Ding, H., Silvestri, S., Chiabai, A., and P.A.L.D. Nunes (2010) "A Hybrid Approach to the Valuation of Climate Change Effects on Ecosystem Services: Evidence from the European Forests", FEEM working paper, No.2010.050

EASAC (2005) A User's Guide to Biodiversity Indicators, European Academies Science Advisory Council, ISBN 0854036121

EEA (2007) "Halting the Loss of Biodiversity by 2010: Proposal for a First Set of Indicators to Monitor Progress in Europe", EEA Technical Report No.11/2007

Ehrlich, P.R. (1988) "The Loss of Diversity: Causes and Consequence Biology, and the Future of Humanity" in Wilson, E.O. (ed.) Biodiversity, National Academy Press, Washington DC.

Faith, D.P. (2005) "Global Biodiversity Assessment: Integrating Global and Local Values and Human Dimensions", Global Environmental Change 15: 5-8

Giller, P.S. and G. O'Donovan (2002) “Biodiversity and Ecosystem Function: Do Species Matter?", Biology and Environment: Proceedings of the Royal Irish Academy 102B (3): 129-139

IPCC (2000). Special Report on Emissions Scenarios. Nebojsa Nakicenovic and Rob Swart (Eds.), Cambridge University Press, UK. Available online at: http://www.ipcc.ch/ipccreports/sres/emission/index.htm

IPCC (2001). Intergovernmental Panel on Climate Change, Climate Change 2001: The Scientific Basis. Cambridge University Press, Cambridge, UK, pp. 881

Kontoleon, A., Pascual, U. and T. Swanson (2007), Introduction. In: A. Kontoleon, U. Pascual and T. Swanson, Editors, Biodiversity Economics: Principles, Methods and Applications, Cambridge University Press, Cambridge.

Leadley, P., Pereira, H.M., Alkemade, R., Fernandez-Manjarrés, J.F., Proença, V., Scharlemann, J.P.W., Walpole, M.J. (2010) Biodiversity Scenarios: Projections of 21st century change in biodiversity and associated ecosystem services. Secretariat of the Convention on Biological Diversity, Montreal. Technical Series no. 50, 132 pages.

Lindner M. et al (2008) "Impacts of Climate Change on European Forests and Options for Adaptation", Report to the European Commission Directorate - General for Agricultural and Rural Development, contract nr. AGRI-2007-G4-06, European Commission.

Loreau, M., Naeem, S., Inchausti, P., Bengtsson, J., Grime, J.P., Hector, A., Hooper, D.U., Huston, M.A., Raffaelli, D., Schmid, B., Tilman, D., and D.A. Wardle (2001) "Biodiversity and Ecosystem Functioning: Current Knowledge and Future Challenges", Science 294: 804-808

Mace, G. M. and J.E.M. Baillie (2007) "The 2010 Biodiversity Indicator: Challenges for Science and Policy”. Conservation Biology, 21(6): 1406-1413

Martens P., Rotmans J., and D. de Groot (2003) “Biodiversity: Luxury or Necessity?”. Global Environmental Change 13: 75-81

MCPFE, 2007. State of Europe's forests 2007: The MCPFE report on sustainable forest management in Europe, Ministerial Conference on the Protection of Forests in Europe, Liaison Unit Warsaw, Poland. ISBN: 83-922396-8-7 or 978-83-922396-8-0

Millennium Ecosystem Assessment (2005). Ecosystems and Human Well-being: Synthesis. Island Press, Washington, DC. Copyright @ 2005 World Resources

Molnár Zs, Bartha S, Seregélyes T, Illyés E, Botta-Dukát Z, Tímár G, Horváth F, Révész A, Kun A \& Bölöni J: Folia Geobotanica, 2007, 42, 225-247. 
Nijkamp, P. Vindigni, G. and P.A.L.D. Nunes (2008) "Economic Valuation of Biodiversity: A Comparative Study", Ecological Economics vol 67: 217-231

Nunes, P.A.L.D and J.C.J.M van den Bergh (2001) "Economic Valuation of Biodiversity: Sense or Nonsense?" Ecological Economics vol.39 (2): 203-222

Paine, R.T (2002) “Tropic Control of Production in a Rocky Intertidal Community”, Science 296: 736-739.

Pereira, H.M., Leadley, P.W., Proença1, V., Alkemade,R., Scharlemann, J.P.W., FernandezManjarrés, J.F., Araújo, Miguel B., Balvanera, P., Biggs, R., Cheung, W.W.L., Chini, L., Cooper, H.D., Gilman, E.L., Guénette, S., Hurtt, G.C., Huntington, H.P., Mace, G.M., Oberdorff, T., Revenga, C., Rodrigues, P., Scholes, R.J., Sumaila, U.R. and M. Walpole (2010) "Scenarios for Global Biodiversity in the $21^{\text {st }}$ Century", Science 330: 1496-1501

Perrings, C.A., Maler, K.G.Folke, C., Holling, C.S. and B.O. Jansson (1995) "Biodiversity Conseravtion and Economic Development: The policy Problem" in Perrings et al. (eds.) Biodiversity Conservation: problems and policies, Kluwer Academic Publishers, the Netherlands.

POST (2008) “Biodiversity Indicator”, Postnote, July 2008 Number 312, parliamentary Office of Science and Technology, UK.

Sceretariate of the Convention on Biological Diversity (2009) "Connecting Biodiversity and Climate Change Mitigation and Adaptation: Report of the Second Ad Hoc Technical Expert Groupo on Biodiversity and Climate Change" Montreal, Technical Series No.41, 126 pages.

Schmid, B., Joshi, J. and F. Schläpfer (2000) "Empirical Evidence for Biodiversity-Functioning relationships", in A.P.Kinzig, D. Tilman and S.W. Pacala (eds), Functional Consequences of Biodiversity: Experimental Progress and Theoretical Extensions, 120-50. Monographs in Populaiton Biology 33. Princeton, NJ. Princetion University Press.

Schöter D., Cramer W., Leemans R., Prentice I. C., Araùjo M. B., Arnell N. W., Bondeau A., Bugmann H., Carter T. R., Gracia C. A.,. de la Vega-Leinert A. C, Erhard M., Ewert F., Glendining M., House J. I., Kankaanpää S., Klein R. J. T., Lavorel S., Lindner M., Metzger M. J., Meyer J., Mitchell T. D., Reginster I., Rounsevell M., Sabaté S., Sitch S., Smith B., Smith J., Smith P., Sykes M. T., Thonicke K., Thuiller W., Tuck G., Sönke Zaehle, Bärbel Z., 2005. Ecosystem Service Supply and Vulnerability to global change in Europe. Science 310: 1333-1337.

Ten Brink ,B. (2000). ) "Biodiversity Indicators for the OECD Environmental Outlook and Strategy", GLOBIO Report Series No. 25., RIVM, 2000. http://www.rivm.nl/bibliotheek/rapporten/402001014.pdf.

Verbeek, Marno (2000) A guide to modern econometrics. John Wiley \& Sons, Ltd, ISBN 0-47189982-8

Walther G., Post, E., Convey, P., Menzel, A., Parmesan, C., Beebee, T.J.C., Fromentin, J., HoeghGuldbergy, O., and F. Bairlein (2002) "Ecological Responses to Recent Climate Change", Nature, vol 416: 389-395

Willims W.D. et al. (2002) "Response of the Mixed Prairie to Protection from Grazing", J. Range Manage 55: 210-216. 


\section{BC3 WORKING PAPER SERIES}

\section{Basque Centre for Climate Change (BC3), Bilbao, Spain}

The BC3 Working Paper Series is available on the internet at the following address:

http://www.bc3research.org/lits publications.html

http://ideas.repec.org/s/bcc/wpaper.html

Recent BC3 Working Papers available:

2012-01 Roger Fouquet: Trends in Income and Price Elasticities of Transport Demand (18502010)

2012-02 Sébastien Foudi: Exploitation of soil biota ecosystem services in agriculture: a bioeconomic approach

2012-03 Mikel González-Eguino, Anil Markandya and Marta Escapa: From shadow to green: Linking environmental fiscal reform and the informal economy

2012-04 Anil Markandya, Mikel González-Eguino and Marta Escapa: Environmental fiscal reform and unemployment in Spain

2012-05 Dirk Rübbelke and Stefan Vögele: Effects of Carbon Dioxide Capture and Storage in Germany on European Electricity Exchange and Welfare

2012-06 Eneko Garmendia and Gonzalo Gamboa: Weighting social preferences in participatory multi-criteria evaluations: a case study on sustainable natural resource management.

2012-07 Ferdinando Villa, Ken Bagstad, Gary Johnson, Brian Voigt: Towards a Comprehensive Approach to Quantifying and Mapping Ecosystem Services

2012-08 Roger Fouquet: Economics of Energy and Climate Change: Origins, Developments and Growth

2012-09 Maria-Angeles Diez, Iker Etxano, Eneko Garmendia: Evaluating Governance and Participatory Processes in Natura 2000: Lessons Learned and Guidance for Future Prospects

2012-10 Iker Etxano, Eneko Garmendia, Unai Pascual. David Hoyos, Maria-Angeles Diez, José A. Cadiñanos, Pedro J. Lozano: Towards a Participatory Integrated Assessment Approach for Planning and Managing Natura 2000 Network Sites

2012-11 Luis M. Abadie and José M. Chamorro: Valuation of Wind Energy Projects: A Real Options Approach

2012-12 Helen Ding and Paulo A.L.D. Nunes: Modeling the Links between Biodiversity, Ecosystem Services and Human Wellbeing in the context of Climate Change: Results from an Econometric Analysis on the European Forest Ecosystems 